\title{
COMMENTARY
}

\section{To overcome two diseases with one pill}

\author{
Masaki Mogi and Masatsugu Horiuchi \\ Hypertension Research (2016) 39, 399-400; doi:10.1038/hr.2016.3; published online 28 January 2016
}

$\mathrm{H}$ ypertension and type 2 diabetes mellitus and/or obesity often coexist. Diabetes and obesity sometimes cause drug-resistant hypertension. Moreover, several antidiabetic drugs such as sulfonylureas, glinides and glitazones, as well as insulin increase body weight and often make it difficult to manage body weight in diabetic patients. Therefore, hypertensive patients with diabetes are not only at higher risk for cardiovascular disease, but also require multidrug therapy for better management. Sodium-glucose cotransporter-2 (SGLT2) inhibitors are a new class of diabetic medication that target renal reabsorption of glucose and promote normal glucose levels associated with weight loss, and act as osmotic diuretics, resulting in lowering of blood pressure (BP). Clinical benefits of SGLT2 inhibitors have been reported recently. For example, Tikkanen et al. ${ }^{1}$ reported that an SGLT2 inhibitor, empagliflozin, was associated with significant and clinically meaningful reductions in BP and $\mathrm{HbAlc}$ level compared with placebo in hypertensive patients with diabetes. Moreover, very recently, a placebo-controlled cardiovascular outcome trial of empagliflozin (EMPA-REG OUTCOME) demonstrated that type 2 diabetic patients treated with empagliflozin showed a lower rate of the primary composite cardiovascular outcome and of death from any cause as compared with placebo, ${ }^{2}$ proving that SGLT2 inhibitors have a beneficial effect beyond glycemic control. The BP reduction of $\sim 4 \mathrm{~mm} \mathrm{Hg}$ in the empagliflozin group compared with the placebo group shown in supplemental data of this article may be involved in the SGLT2 inhibitor-induced reduction of cardiovascular

M Mogi and M Horiuchi are at Department of Molecular Cardiovascular Biology and Pharmacology, Ehime University, Graduate School of Medicine, Ehime, Japan E-mail: mmogi@m.ehime-u.ac.jp risk; however, the details are not elucidated to date.

In the present study, Takeshige et al. ${ }^{3}$ demonstrated a preventive effect of empagliflozin on abnormal circadian rhythm of BP in salt-treated obese Otsuka Long Evans Tokushima Fatty (OLETF) rats. One of the mechanisms of the improvement of BP circadian rhythm by empagliflozin treatment is a reduction of water retention. As shown in this study, empagliflozin treatment prevented the elevation of 24-h mean arterial pressure (MAP) compared with vehicle treatment, mainly due to reduced MAP in the inactive period', suggesting that reduced volume retention by empagliflozin has an important role in $\mathrm{BP}$ reduction during the sleeping time, such as nocturnal BP in humans. Recently, nocturnal BP has been highlighted. Mean nocturnal BP level is the most sensitive predictor of cardiovascular morbidity and mortality. The pathophysiology of nocturnal BP increase is multifactorial, such as volume retention, sympathovagal imbalance and disturbed breathing during sleep etc., as reviewed by Yano et al. ${ }^{4}$ High-sodium intake is directly related to water retention and disturbs the circadian rhythm of renal sodium excretion in non-dipper type essential hypertension. ${ }^{5}$ Takeshige et al. also showed that treatment with empagliflozin increased urinary sodium excretion in a sodium challenge test. Therefore, natriuresis by empagliflozin may be involved in the improvement of BP circadian rhythm. However, in OLETF rats treated with empagliflozin, sodium excretion was increased only during the first day $(0-24 \mathrm{~h})$, and not during 2-3 days after sodium administration. Interestingly, Lin et al. ${ }^{6}$ also reported that sodium excretion was significantly increased in $\mathrm{db} / \mathrm{db}$ mice $24 \mathrm{~h}$ after empagliflozin treatment, but did not differ between the control and empagliflozin groups from day 2 .
These results suggest that the effect of SGLT2 inhibitors on natriuresis is acute and transient; therefore, other mechanisms may be involved in the change of BP circadian rhythm other than natriuresis. Our group also reported recently that renal sympathetic denervation improves glucose metabolism through an increase in the tissue glucose uptake and glycosuria induced by SGLT2 suppression. $^{7}$ On the other hand, Kim et al. ${ }^{8}$ also showed that adrenaline decreased SGLT2 protein level. Cherney et al. ${ }^{9}$ reported that treatment with empagliflozin reduced arterial stiffness in young type 1 diabetic patients due to pleiotropic actions of SGLT2 inhibition; however, sympathetic nerve system activity (s.d. of normal-tonormal interval, and plasma noradrenaline and adrenaline levels) was not changed. On the other hand, Takatori et al. demonstrated that the abnormal innervation of perivascular nerves in mesenteric resistance arteries induced by chronic hyperinsulinemia disturbs the neuronal regulation of vascular tone and may cause hypertension in OLETF rats. Therefore, SGLT2 inhibition-induced prevention of hyperinsulinemia may prevent changes in the distribution of sympathetic nerve fibers. ${ }^{10}$ Although it is not well known whether SGLT2 'inhibition' contributes to preventing sympathetic hyperactivity or not, there may be some interactions between SGLT2 and sympathetic nerve activation.

A link between circadian clock genes and metabolic syndrome, including hypertension has been highlighted. Moreover, higher circadian genetic risk scores generated by counting the risk alleles were observed in patients with non-dipper hypertension than in those with dipper hypertension among young-onset hypertension. ${ }^{11}$ For example, Per1 is implicated in the circadian clock controlling sodium balance through regulation of the renal epithelial sodium 
channel. ${ }^{12}$ Takeshige et al. also investigated clock genes in the kidney, such as Bmal1, Per1 and Per2. The results showed no change in their expression by empagliflozin treatment. However, they did not investigate other clock genes such as Crys. Cry1/2-null mice exhibit salt-sensitive hypertension due to abnormally high synthesis of aldosterone by the adrenal gland. ${ }^{13}$ Moreover, Kovanen et al. ${ }^{14}$ reported that Cryl genetic variants may have a role in elevated BP and hypertension. Although plasma aldosterone level was not changed in empagliflozin-treated OLETF rats in the present study, the expression of Crys after empagliflozin treatment was not investigated. Thus, the more detailed mechanism of SGLT2 inhibitor-induced improvement of BP circadian rhythm should be elucidated, including other clock gene regulation, in the future.

Medication adherence is important for reducing hospitalization due to cardiovascular disease and mortality. ${ }^{15}$ Versatile drugs have been expected to improve adherence to evidence-based cardiovascular medication. SGLT2 inhibitors may become one of the contributing drugs for patients with hypertension and diabetes, and as a versatile drug it has to be used carefully to avoid side effects.

\section{CONFLICT OF INTEREST}

The authors declare no conflict of interest.

\section{ACKNOWLEDGEMENTS}

This study was supported by JSPS KAKENHI

(grant number 25293310 to MH, 25462220 to MM, $15 \mathrm{~K} 19974$ to JI and 26860567 to L-JM).

1 Tikkanen I, Narko K, Zeller C, Green A, Salsali A, Broedl UC, Woerle HJ. Empagliflozin reduces blood pressure in patients with type 2 diabetes and hypertension. Diabetes Care 2015; 38: 420-428.

2 Zinman B, Wanner C, Lachin JM, Fitchett D, Bluhmki E, Hantel S, Mattheus M, Devins $T$, Johansen OE, Woerle HJ, Broedl UC, Inzucchi SE. Empagliflozin, cardiovascular outcomes, and mortality in type 2 diabetes. N Engl J Med 2015; 373: 2117-2128.

3 Takeshige $Y$, Fujisawa Y, Rahman A, Kittikulsuth W, Nakano D, Mori H, Masaki T, Ohmori K, Kohno M, Ogata H, Nishiyama A. A sodium-glucose co-transporter 2 inhibitor empagliflozin prevents abnormality of circadian rhythm of blood pressure in salt-treated obese rats. Hypertens Res 2016; 39: 415-422.

4 Yano Y, Kario K. Nocturnal blood pressure and cardiovascular disease: a review of recent advances. Hypertens Res 2012; 35: 695-701.

5 Kimura G, Dohi Y, Fukuda M. Salt sensitivity and circadian rhythm of blood pressure: the keys to connect CKD with cardiovascular events. Hypertens Res 2010; 33: 515-520.

6 Lin B, Koibuchi N, Hasegawa Y, Sueta D, Toyama K, Uekawa K, Ma M, Nakagawa T, Kusaka $H$, Kim-Mitsuyama S. Glycemic control with empagliflozin, a novel selective SGLT2 inhibitor, ameliorates cardiovascular injury and cognitive dysfunction in obese and type 2 diabetic mice. Cardiovasc Diabetol 2014; 13: 148.

7 Rafiq K, Fujisawa Y, Sherajee SJ, Rahman A, Sufiun A, Kobori $H$, Koepsell H, Mogi M, Horiuchi M, Nishiyama A. Role of the renal sympathetic nerve in renal glucose metabolism during the development of type 2 diabetes in rats. Diabetologia 2015; 58 2885-2898.
8 Kim EJ, Lee YJ, Lee JH, Han HJ. Effect of epinephrine on alpha-methyl-D-glucopyranoside uptake in renal proximal tubule cells. Cell Physiol Biochem 2004; 14: 395-406.

9 Cherney DZ, Perkins BA, Soleymanlou N, Har R, Fagan N, Johansen OE, Woerle HJ, von Eynatten $M$, Broedl UC. The effect of empagliflozin on arterial stiffness and heart rate variability in subjects with uncomplicated type 1 diabetes mellitus. Cardiovasc Diabetol 2014; 13: 28.

10 Takatori S, Fujiwara H, Zamami Y, Hashikawa-Hobara N, Kawasaki $\mathrm{H}$. Decreased perivascular CGRP-containing nerves in Otsuka Long-Evans Tokushima Fatty rats with insulin resistance and hypertension. Hypertens Res 2014; 37: 398-404.

11 Leu HB, Chung CM, Lin SJ, Chiang KM, Yang HC, Ho HY, Ting CT, Lin TH, Sheu SH, Tsai WC, Chen JH, Yin WH, Chiu TY, Chen Cl, Fann CS, Chen YT, Pan WH, Chen JW. Association of circadian genes with diurnal blood pressure changes and non-dipper essential hypertension: a genetic association with young-onset hypertension. Hypertens Res 2015; 38 : $155-162$.

12 Gumz ML, Stow LR, Lynch IJ, Greenlee MM, Rudin A, Cain BD, Weaver DR, Wingo CS. The circadian clock protein Period 1 regulates expression of the renal epithelial sodium channel in mice. J Clin Invest 2009; 119: 2423-2434.

13 Doi M, Takahashi Y, Komatsu R, Yamazaki F, Yamada $\mathrm{H}$, Haraguchi S, Emoto N, Okuno $\mathrm{Y}$, Tsujimoto G, Kanematsu A, Ogawa O, Todo $T$, Tsutsui K, van der Horst GT, Okamura $H$. Salt-sensitive hypertension in circadian clock-deficient Cry-null mice involves dysregulated adrenal Hsd3b6. Nat Med 2010; 16: 67-74.

14 Kovanen L, Donner K, Kaunisto M, Partonen T. Cry1, Cry2 and PRKCDBP genetic variants in metabolic syndrome. Hypertens Res 2015; 38: 186-192.

15 Shin S, Song H, Oh SK, Choi KE, Kim H, Jang S. Effect of antihypertensive medication adherence on hospitalization for cardiovascular disease and mortality in hypertensive patients. Hypertens Res 2013; 36: 1000-1005. 